\title{
The CSO Sector in Hungary and Certain European Particularities
}

\begin{abstract}
Summary
Civil life works well and is highly active in Hungary, as presented by the authors supported by statistical data. In terms of their activities, organisational sizes and locations, associations and foundations in today's Hungary give an extremely diverse picture. Year by year, the financial opportunities available for the civil sector increase and resources are provided for the proactive performance of their tasks. Overall, state aid, which has increased to more than 2.5 times of its original amount since 2010, has been able to effectively support the favourable developments that have taken place in this sector, and this helps the lives of many of us, making them more useful and productive, precisely because of the diversity of civil activities. Compared to other countries in the region, we can see that the legal and organisational framework of civil autonomy is ensured at a high level in Hungary, and in terms of content, community building is of paramount importance in everyday life.
\end{abstract}

Journal of Economic Literature (JEL) codes: D71, L3, L31

Keywords: CSO sector, civil autonomy, community building, foundations, associations

Vince Szalay-Bobrovniczky, Deputy Secretary of State responsible for Civic and Social Affairs at the Prime Minister's Office, PÉTER Kecskés, Head of the Department responsible for the area of civil society within the same organisational unit of the Prime Minister's Office. 
One of the key characteristics of civil society organisations is that they do not exist for themselves, but that in essence, they have been brought into being by needs outweighing the individual possibilities of the persons and organisations that established them and there is always some kind of intent behind their establishment to serve the community. Such intent may be to serve one or more communities, or just to express their will and sense of cohesion.

The associations and foundations serving truly meaningful purposes that actively take part in building communities and achieving community goals with societal value and which thus create significant value are especially important to the Hungarian Government. In many cases such organisations have a considerable number of members who are embedded in the local community and who are known by the people locally and perhaps even nationally, and are often helped by them in the CSOs' work as volunteers. (Presently some 400,000 volunteers are working in CSOs across Hungary.) The civil society organisations and communities in question are thus organisations and communities that it is good and worth belonging to. Such civil society organisations often take a load off the shoulders of the State or local governments and are able to provide considerable assistance locally with their activities and work.

Whether an activity concerns families, social affairs, healthcare, leisure, youth, sport or any other useful and valuable activity, CSOs in effect help participating members and their smaller or larger circles of acquaintances, as well as make their lives more comfortable and liveable. Their added value and their usefulness to society are thus indisputable.

According to the Hungarian Central Statistical Office's (KSH) most recent data (from 2018) the number of civil society and other non-profit organisations in Hungary is 61,491 , where the number of classic civil society organisations (foundations, associations) is 53,758 . The ratio of civil society organisations in Hungary with their registered offices in Budapest is $21.7 \%$, those with registered offices in county seats and towns is $51.7 \%$, while those with registered offices in villages is $26.6 \%$. The number of civil society organisations operating in villages has been steadily rising since 2016.

Civil society organisations are involved in a variety activities with the following areas covering close to $86 \%$ of their activities: sports $(15.8 \%)$, culture $(15.7 \%)$, leisure, hobbies $(15 \%)$, education $(13.1 \%)$, social care $(8.9 \%)$, development of cities, towns and villages and representation of professional and economic interests (4.9-5\%), healthcare $(4.1 \%)$ and environmental protection $(3.4 \%)$.

By now, only $0.3 \%$ of the organisations are active within the area of politics (the figure for 2017 was $0.5 \%$ ), while the ratio of organisations involved in legal protection has remained $0.9 \%$. Other activities of CSOs cover the areas of environmental protection, public safety and civil protection, economic development, religion and research.

The annual revenues of the classic CSO sector have been on the rise since 2010. Based on data from 2018, State aid has shown an increase of 30.3\% compared to resources in 2017 and at the same time private support has also risen by $21.2 \%$. The extent of State aid flowing into the classic CSO sector increased from HUF 144 billion per year to HUF 370 billion per year, that is, over two-and-a-half fold between 2010 
Vince Szalay-Bobrowniczky, Péter Kecskés: The CSO Sector in Hungary...

Figure 1: The activities of CSOs in $2018(\%)$

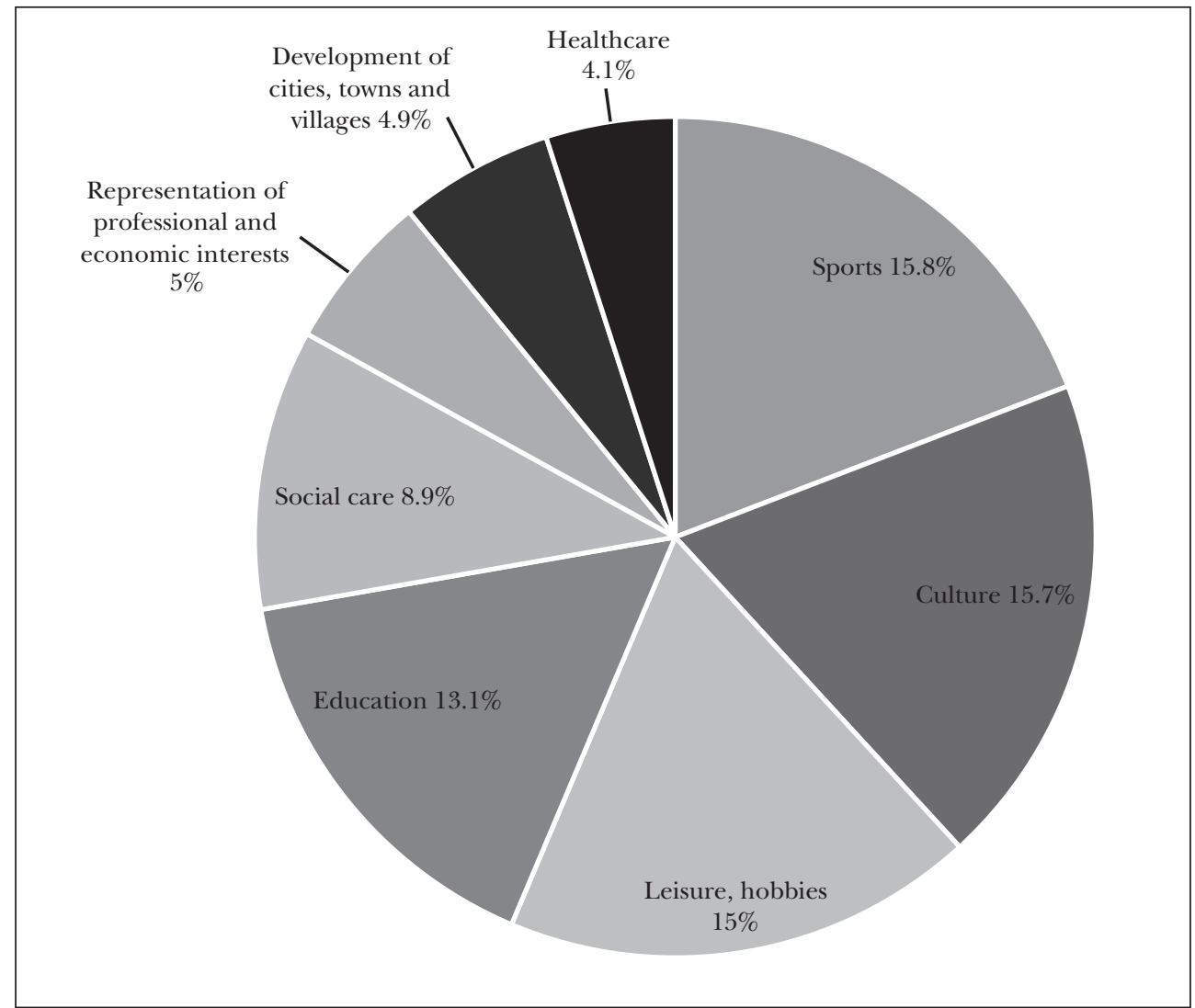

Source: By the author

and 2018. Revenues from abroad have shown an increase of $42 \%$ compared to figures from 2017, where revenues from EU programmes and aid increased over two fold and revenues from non-profit organisations, churches and parties have shown an increase of $9.7 \%$.

Table 1: The annual revenues of CSO sector (Data in HUF billion)

\begin{tabular}{l|c|c|c|c|c|c|c|c|c|c|c|c}
\hline & $\mathbf{2 0 0 7}$ & $\mathbf{2 0 0 8}$ & $\mathbf{2 0 0 9}$ & $\mathbf{2 0 1 0}$ & $\mathbf{2 0 1 1}$ & $\mathbf{2 0 1 2}$ & $\mathbf{2 0 1 3}$ & $\mathbf{2 0 1 4}$ & $\mathbf{2 0 1 5}$ & $\mathbf{2 0 1 6}$ & $\mathbf{2 0 1 7}$ & $\mathbf{2 0 1 8}$ \\
\hline $\begin{array}{l}\text { Revenues from core } \\
\text { activities and management }\end{array}$ & 156 & 167 & 168 & 167 & 176 & 185 & 178 & 179 & 181 & 213 & 235 & 250 \\
\hline State aid & 131 & 143 & 145 & $\mathbf{1 4 4}$ & 138 & 151 & 160 & 175 & 202 & 240 & 284 & $\mathbf{3 7 0}$ \\
\hline Private support & 97 & 97 & 101 & 109 & 128 & 147 & 182 & 196 & 187 & 166 & 165 & 200 \\
\hline $\begin{array}{l}\text { Total revenue } \\
\begin{array}{l}\text { State +private +core } \\
\text { activities+management) }\end{array}\end{array}$ & $\mathbf{3 8 4}$ & $\mathbf{4 0 7}$ & $\mathbf{4 1 4}$ & $\mathbf{4 2 0}$ & $\mathbf{4 4 2}$ & $\mathbf{4 8 3}$ & $\mathbf{5 2 0}$ & $\mathbf{5 5 0}$ & $\mathbf{5 7 0}$ & $\mathbf{6 1 9}$ & $\mathbf{6 8 4}$ & $\mathbf{8 2 0}$ \\
\hline
\end{tabular}

Source: By the author 
Some 12 different types of State aid are known. These include pro rata budgetary support, support provided from central funds or social security funds, support provided through corporate tax or income from VAT reimbursements. Civil society organisations may also receive resources from State-owned companies, such as Szerencsejáték Zrt, which, for instance, supported the National Cultural Fund of Hungary with HUF 9.2 billion in 2018. (Revenues from gambling play an important role in supporting the CSO sector primarily in Scandinavian countries, but we will touch upon this later.)

Two special forms of State aid provided to classic CSOs are the National Cooperation Fund (NEA) and the option to dispose of $1 \%$ of the personal income tax (SZJA). The NEA is supervised by the Prime Minister's Office as the CSO fund of the Hungarian Government, thus it is the only source of budgetary financing that accepts applications from CSOs exclusively. Ministries and local governments also support CSOs abundantly, but funds operated by them may also be applied to by public institutions.

The NEA is a form of CSO financing established under "Act CLXXV of 2011 on the right of association, non-profit status and operating and supporting civil society organisations" (CSOs Act) that supports the operation and professional activities of CSOs and where CSOs may apply not only for grants to fund their operational costs and professional programmes, but where CSOs are also eligible for State aid based on donations they have collected. Independent NEA bodies appointed for four years make decisions concerning $85 \%$ of the NEA envelope, while commitments have been made concerning the [remaining] $15 \%$ based on individual grant applications approved by the Minister heading the Prime Minister's Office since 2019. (The NEA and thus its envelope for individual grants was assigned to the Ministry of Human Capacities until 2018 and accounted for $10 \%$ of all resources. The law was amended in 2019 to set the rate at $15 \%$.)

In Europe, the option to offer $1 \%$ of one's personal income tax was first introduced in Hungary. Private individuals paying personal income tax in Hungary may instruct how $1 \%$ of their tax should be used based on Act CXXVI of 1996 "on the use of a specified amount of personal income tax in accordance with the taxpayer's instruction" since 1997. It is also possible to offer $1 \%$ of one's taxes to a recognised church since 1998, thus the current system, which allows $1+1 \%$ of the personal income tax to be offered, has been operational in Hungary for 22 years. Each year, instructions may be given concerning the use of $1+1 \%$ of one's taxes up to 20 May, that is, the deadline for submitting personal income tax returns: every private individual may offer $1 \%$ to a registered $\mathrm{CSO}$ and another $1 \%$ to a religious community with a technical number or the National Talent Programme. The advantage of this system is that citizens are able to provide targeted resources directly to certain organisations preferred by them without imposing any financial burden on themselves. Several European countries have found this initiative to be advantageous and by now there are options to offer certain parts of one's taxes in Czechia, Italy, Spain, Poland, Latvia, Macedonia, Moldova and Slovakia, among others.

It should be noted that an amount corresponding to $1 \%$ of the (total) current personal income tax is transferred to the CSO sector under all circumstances, a part 
Vince Szalay-Bobrovniczky, Péter Kecskés: The CSO Sector in Hungary...

according to the taxpayers' instructions directly, and the "remainder" through support from the NEA.

$85 \%$ of the support granted by the NEA is awarded through calls for proposals under the provisions of the CSO Act in order to ensure the independence of the support scheme. In part representatives selected by CSOs make up the five boards, each with nine members, which prepare the calls for proposals of the NEA, assess the applications received and verify the achievement of the supported objectives from a professional perspective. The activities supported by the five boards cover the entire CSO sector.

Since 2015, the appropriations of the NEA have depended on the total amount of the offers of $1 \%$ of personal income tax under Section 58(5) of the CSO Act. The NEA's resources are equal to the difference between the amount that could have been offered to CSO beneficiaries in the second year prior to the given budgetary year and the amount actually allocated to them. The table 2 shows the total financial appropriations of the NEA from 2012.

Table 2: Appropriations of the NEA

\begin{tabular}{c|c|c|c|c|c|c|c|c|c}
\hline \multicolumn{1}{c|}{ Year } & $\mathbf{2 0 1 2}$ & $\mathbf{2 0 1 3}$ & $\mathbf{2 0 1 4}$ & $\mathbf{2 0 1 5}$ & $\mathbf{2 0 1 6}$ & $\mathbf{2 0 1 7}$ & $\mathbf{2 0 1 8}$ & $\mathbf{2 0 1 9}$ & $\mathbf{2 0 2 0}$ \\
\hline $\begin{array}{l}\text { Total financial ap- } \\
\text { propriations of the } \\
\text { NEA (HUF billion) }\end{array}$ & 3.38 & 3.38 & 3.38 & 5.406 & 4.896 & 5.267 & 5.256 & 5.928 & 7.723 \\
\hline
\end{tabular}

Source: By the author

The boards conduct a substantive assessment of the greater part of the support granted through calls for proposals and then take a decision. In the case of certain calls for proposals (simplified calls for proposals, pro rata calls for proposals) only the form is checked and every application that is submitted in valid form wins until the envelope is depleted. Among others, the CSOs operating in the following fields belong to the specific boards:

- Board of social environment: Public education, science and research, vocational and adult education, cultural activities;

- Board of mobility and adaptation: Security of life and property, public safety, volunteer firefighting, leisure, hobbies and sports;

- Board of national cohesion: Cooperation within the Carpathian basin, fostering of religious activities, other cultural activities (music, dance, folk music, folk dance);

- Board of social responsibility: Grant-giving, social services, care for the elderly, rehabilitative care, protection of nature and the environment;

- Board for the future of future generations: Education, child development, child and youth protection, health promotion, drug prevention.

Approximately 10-12 thousand applications were submitted annually to the NEA in recent years and of these, approximately 5-6 thousand applications won. Every board provides an opportunity in some form or other to CSOs of Hungarians living outside of Hungary (for example as co-applicants) to submit applications. 
In Hungary, civic life has considerable traditions steeped in history. The first CSOs were established as early as the mid-19th century by count István Széchenyi and thriving civic life could be witnessed between the two world wars. This process was broken during the communist era, but following the change in the regime the process regained its strength.

In terms of figures, the 61,000 CSOs currently operating in Hungary place Hungary in the upper third of the European average, but a few figures should provide a comparison to be able to place Hungary in the proper context: while in Portugal, which has an almost identical number of inhabitants as Hungary, only 17,000 registered CSOs are active, this number is 135,000 in the Czech Republic, which has slightly more than 10 million inhabitants, and 115,000 in Norway, which has close to 6 million inhabitants. Both of these figures, which are considerably higher than the Hungarian figure, are presumably due to reasons of how their societies are organised, that is, in these cases we are faced with "bottom-up" societies, while Hungary has been more statist traditionally. For instance, in Norway almost every political leader started their careers at an NGO and these organisations are supported as abundantly as possible in a country that is quite rich anyway, resulting in most politicians returning for some time to these civil society organisations once their active years are over or after their political parties have handed over power.

Regarding the number of civil society organisations, we must mention France, where an outstanding number of 1.5 million registered organisations are active. This means that there is one CSO for every 45 citizens. Regarding the (country) with an outstanding figure in our region, Czechia, this figure is close to 80, while it is 160 for Hungary.

Concerning the management of a State fund, there are barely any other European countries which have a State fund reserved for civil society organisations comparable to the NEA, with the exception of Poland, for example, and the particular, but efficient system achieved by Latvia, which is operated somewhat differently from that of Hungary.

An institution similar to the NEA, the Council of the National Freedom Institute - Centre for Civil Society Development (NIW-CRSO) was established in Poland in 2017, which disposes of approximately HUF 5 billion annually and operates through five different programmes. Besides the NIW, the Polish National Foundation should also be highlighted: between 2016 and 2027, this governmental civic foundation may spend 45 billion on supporting non-profit civil society organisations operating in the public interest.

Latvia has in effect out-sourced the tasks carried out by the NEA to a public foundation (Society Integration Foundation - SIF), the professional supervision of which falls within the remit of the Prime Minister's Office. Eleven members were appointed to the governing board of the public foundation, including five ministers, five NGO members and one advisor - seven members must vote the same way for the SIF's decision to be final, thus seen from another perspective, at least one NGO is needed to support the State's will. By contrast, in Hungary the Council and the boards of the 
Vince Szalay-Bobrovniczky, Péter Kecskés: The CSO Sector in Hungary...

NEA are completely independent - regarding $85 \%$ of its resources - no public authority may fiddle with their work under the law, however, the Prime Minister's Office takes decisions concerning the remaining $15 \%$.

Based on the foregoing, there is no central State-owned civic foundation in most European countries that is similar to the NEA in Hungary, but this should not be construed as either a positive or negative feature of their support schemes. The fact of the matter is that in Europe various governmental bodies provide considerable support to foundations and associations without a central State-owned fund, but this work is primarily carried out in a decentralised manner. Accordingly, specialised ministries with national competence usually have CSO funds and this is the same in the case of States with federal systems and their provincial governments: each provides appropriate resources to the CSOs operating within their remit or specialisation. For example, in Germany 700 different calls for proposals provide resources to CSOs.

As we have indicated above, the NEA, or the CSO fund of the Hungarian Government will be able to provide close to HUF 10 billion to the CSO sector next year, but considerably more funds flow to foundations and associations within the Hungarian system annually: the amount allocated by the State within the sector was HUF 370 billion in 2018. By comparison let us indicate a figure from this region (Czechia), as the support granted there was the equivalent of HUF 215 billion in the same year and let us take a look at Sweden, the modern age cradle of civil society, where an amount that is equivalent to more than HUF 400 billion was allocated within the sector in 2018. All this shows that Hungary has no reason to be ashamed of its amounts either, as Hungary is able to meet a challenge coming even from richer western States.

Civil society organisations' income isn't capped either in Hungary or generally in Europe, as they may accept as much in resources as they wish, but they must naturally render their accounts strictly. Luxembourg is an interesting exception in this respect as well: based on the traditions of the Napoleonic Civil Code, private civic initiatives are not encouraged, thus for instance in the Grand Duchy only the State may establish non-profit foundations. But they also have their separate ways regarding capped incomes: a donation or aid to a CSO that exceeds EUR 30,000 is dependent on political approval, as the Minister for Justice of Luxembourg must counter-sign it.

In essence, Hungarian law and practice do not make a distinction between support according to the specific areas of civic life it is provided to, that is, sports, education, culture or other activities. No doubt the general classification of larger civil society organisations carrying out tasks that are especially in the public interest under a separate budget line (such as the National Association of Large Families) is also a political/ philosophical decision of the Government and the Government has made this decision because they do not wish to keep these organisations in a kind of uncertainty but rather strive for certainty in order to ensure that tasks in the public interest are carried out. However, in Hungary it is generally not the "importance" of a specialist area that determines how support is allocated, but rather the requirement that the given organisation must perform community work, must create a community and must operate such community - from this perspective it is thus irrelevant how the real or perceived social "use- 
fulness" of an organisation could be graded, the most important factor is supporting a community of people. Even though the Hungarian principle could in many respects be detected in other parts of Europe (primarily with regard to smaller organisations), in most Western European and Northwestern European countries explicitly political priorities are increasingly playing a part when funds are allocated. Thus, in many countries, social integration, that is, the integration of immigrants already living in the country and the integration of newly arriving migrants are important factors. In these countries the area of legal protection also has special importance and in most cases those organisations fulfil a role and receive considerable resources (for example Amnesty International, Transparency International, Helsinki Commission, a classic example in Hungary is the Hungarian Civil Liberties Union (HCLU)), which basically do not receive budgetary funds in Hungary because their activities in Hungary are very political in nature and they oppose the conservative governing forces in a sharp, campaign-like manner. It should be noted that this is not a Hungarian peculiarity, many other Central and Eastern European countries relate to these organisations in a similar manner, as they are acting as the outposts of peculiar political interests in those States as well.

Interesting examples of possible methods for offering one's personal income tax can be found by comparing European countries. As we have seen, in Hungary, one percent of one's personal income tax may be offered to a registered church and another one percent may be offered to an active CSO. By contrast, two times $0.7 \%$ of one's personal income tax may be offered in Spain, the recipient of one may only be the Catholic Church and the recipient of the other may be an institution of the State, thus the latter $0.7 \%$ is directly rechannelled to the Government, even though it originates from the State and thus from the taxpayers. Another notable example is Lithuania, where $2 \%$ of one's personal income tax may be offered to CSOs, and another one percent may be offered to a political party.

We have already said a few words of the diverging and peculiar system of State aid provided to CSOs, thus we have spoken of income originating from diverse tax funds or social security. In several countries the State revenues of gambling considerably contribute to supporting CSOs. This practice has evolved in particular in Northern Europe, thus in Finland, Norway and Estonia, but also in the somewhat Northern country of Poland, where CSOs receive $4 \%$ of gambling revenue compulsorily. Szerencsejáték Zrt. from Hungary is not part of these "statistics" because it does not qualify as a State-owned company, but rather as an economic entity. All the while, as we have already indicated, the Hungarian Szerencsejáték Zrt. provides resources abundantly to the CSO sector, thus, in addition to the 9.2 billion received by the National Cultural Fund of Hungary in 2018, the sports sponsorship scheme received 8.7 billion and the Hungarian National Film Fund received 6.4 billion. The later funds spend the resources they receive to a lesser or greater extent on CSOs.

In summary, it should be highlighted that in Hungary the CSO sector's operation, as well as its financing is colourful and wide-ranging. The financing of specialised areas is balanced, but at continental level there are considerable differences in approach, in Hungary in particular community building is the most important aspect, 
Vince Szalay-Bobrovniczky, Péter Kecskés: The CSO Sector in Hungary...

while in many places in numerous countries across Europe ideological attitudes are more decisive: legal protection, integration and the assistance of migration.

Being of public utility is also an important question everywhere, as CSOs are able to take off a considerable burden from the shoulders of the State and local governments. Certain European countries reward this civic function especially well, there is even a country where a non-profit foundation may only be established by the State (Luxembourg), but this is rather the exception.

Financing models are quite diverse, but in each case the State takes part to a great extent in the support of the sector, specifically for the reason we have stated above: what the State is unable or unwilling to do itself, another smaller unit achieves better and thus providing resources for such unit is ultimately profitable and practical for the State. Although it is not typical of most European countries, it is an important Hungarian particularity that CSOs are able to apply for operating resources in addition to professional support. This is an honest approach as it takes into account that achieving the programmes requires a back office: technical equipment for the organisation, human resources or offices and - in Hungary - the NEA, the CSO fund of the State - among others - provides for a broad range of these.

So many countries, so many rules. Based on our assessment each European system bears certain national characteristics (historic characteristics, regional traditions mingled with historic characteristics or even determinisms dictated by the modern age), but each is democratic and in conformity with EU and local legislation.

The regulation of CSOs in the European Union falls under national competence and this is as it should be. The sector contributes in a significant manner to societal cohesion, but is not of pan-European importance and effect. Therefore, unless a State should apply incomprehensible and senseless restrictive measures against CSOs, we recommend that Brussels should enforce the principle of subsidiarity that is always proclaimed but selectively applied: in other words whatever a larger unit does not want or is not able to carry out, should be achieved by a smaller unit. The Hungarian law concerning the transparency of CSOs (Act LXXVI of 2017 on the transparency of organisations receiving support from abroad), which made it compulsory for CSOs receiving over HUF 7.2 million of financing from abroad to publish data concerning the support they received, was much criticised and was then condemned by the Court of Justice of the European Union. They were subject to no other obligation in addition to this, they could accept any resource, they simply had to comply with transparency requirements. We add that in Italy in the case of foreign resources exceeding approximately HUF 4 million the source of the support must also be published (Section 1(125) of Act 124 of 2017) (to be sure, the source of the support could be foreign or domestic) and - as we have described it above - in Luxembourg, for example, support slightly exceeding HUF 10 million is decided upon by the Minister for Justice, in other words support for CSOs may be capped, if politics so wishes.

Based on the foregoing - as we have implied - we recommend generally enforcing what is prescribed in the basic treaty for the CSO sector, in other words competence lies with the Member States. 